\title{
Theory Talks
}

rament

\section{THEORY TALK \#51}

\section{Yan Xuetong on Chinese ReAlism, THE TSINGHUA SCHOOL OF INTERNATIONAL RELATIONS, AND THE IMPOSSIBILITY OF HARMONY}

\section{Theory Talks}

is an interactive forum for discussion of debates in International Relations with an emphasis of the underlying theoretical issues. By frequently inviting cutting-edge specialists in the field to elucidate their work and to explain current developments both in IR theory and real-world politics, Theory Talks aims to offer both scholars and students a comprehensive view of the field and its most important protagonists.

Citation: Creutzfeldt, B. (2012) 'Theory Talk \#51: Yan Xuetong on Chinese Realism, the Tsinghua School of International Relations, and the Impossibility of Harmony', Theory Talks, http://www.theory-talks.org/2012/11/theory-talk-51.html (28-11-2012) 


\section{YAN XuETONG ON CHINESE REALISM, THE TSINGHUA SCHOOL OF INTERNATIONAL RELATIONS, AND THE IMPOSSIBILITY OF HARMONY}

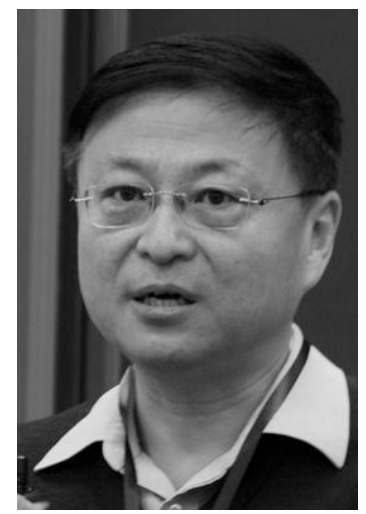

Yan Xuetong is one of most-heard voices in field of IR in China. He identifies himself as a realist, but strongly believes in the need for novel approaches. His work brings to the debate new IR concepts drawn from his study of the political thinkers and social theorists from the 'Golden Age of Chinese Thought'. In this Talk, he elaborates the 'Tsinghua School's approach to IR theory; defends Chinese realism; and discusses China's difficulty in defining her place in the world.

What is, according to you, the central challenge or principal debate in International Relations? And what is your position regarding this challenge/in this debate?

I think the most important debate in IR today is about the relationship between China and the US, that is, the main question is whether the competition between China and the US will result in a disaster - a repetition of the many examples throughout history when two great powers collide-meaning explicitly whether China's rise will lead to wars between the major powers; the second issue is whether it's possible for China to become a new superpower peacefully; and the third issue, thoroughly explored in my book, is whether China will behave like the historical hegemon or whether China will be a new kind of hegemon (Ancient Chinese Thought, Modern Chinese Power, 2011).

Firstly, talking about whether the rise of China will result in a world war, my argument is very clear: it is simply impossible. The reason is not because China is 'nicer' or the Chinese are 'more civilized' than others; rather, the main underlying factor is the destructive power of nuclear weapons. Nuclear weapons prevent nuclear powers from going to war against each other, because that would lead to the total destruction of the human species. That means there are no winners in a nuclear war between two major powers and everyone is a loser. The two powers' rationality insures that neither China nor the US would try to use nuclear war to achieve their goals for increased international status or international dominance. This is why I have great confidence that China's rise does not have any possibility of escalating into world war. Even a smaller scale war is unlikely.

The second question is about whether China can achieve its goals peacefully. That means whether China would use other kinds of warfare. I would tend to say this kind of danger is only slight. I cannot rule it out, but the likelihood is quite small. The reason is-as I outline in the article just published in the Chinese Journal of International Politics [CJIP] - that 'it's a football game rather than a boxing match' (read full article here). If we compare the Cold War 
competition between the United States and the Soviet Union to a boxing match, we might compare that between China and the United States to a game of football. The former was characterized predominately by violence, and whereas the latter will involve occasional conflicts, violence is not the primary means. The victor of Sino-US strategic competition will be the state that can increase its domestic power while at the same time maintaining an appropriate foreign policy strategy.

As for the third question, whether China will behave like the historical hegemon or whether China will be a new kind of hegemon, I think-based on Chinese thought—we can divide 'hegemony' into three types: humane authority, hegemony, and tyranny. Certainly China will not be a tyrannical superpower. As for hegemony, I think China should not behave like the US. China should behave differently from the US, by providing a different type of international leadership for the world. I am advocating for China to be a humane authority. Humane authority is based on both material power and political power. Humane authority needs to have an efficient political system to mobilize both domestic and international resources. Humane means a superpower has more friends and receives more international support than others. China should have more allies than the US, but unfortunately at this moment, we fall far short. Being humane not only requires having an ample number of allies but also being moral and having strong leadership, or as people nowadays like to say, undertaking more international responsibility. Simply stated: being humane means having more friends and having a good political system that can mobilize both domestic and international support. Authority means, first of all, having huge material power and secondly, undertaking more international responsibility. If a state is not capable of using these resources, it means it has no power.

In my book I argue that China should consider what kind of leadership we can provide to the world. China should shift from its focus from economic development to a harmonious society. China should consider placing more emphasis on international responsibility, international leadership and making alliances and moral norms for the world.

\section{How did you arrive at where you currently are in your thinking about IR?}

I started my research of ancient Chinese political thought in 2005. At that time there was a debate in China about whether China should establish a Chinese theory of international relations. Because of my training at Berkeley, I have been strongly influenced by the scientific methodology and believe it is the wrong approach to develop a single IR theory to represent all of China. Deng Xiaoping, the great reformer, coined the phrase, 'socialism with Chinese characteristics'. Subsequently, many people try to use this 'Chinese characteristic' and apply it to develop a new IR theory. However, it is impossible to have a single unified IR theory with Chinese characteristics because China is rich in both population diversity and philosophical thought. Therefore, it is not feasible that a single school of thought or theory could represent the entirety of Chinese thinking. This motivated me to look into the diverse literature of ancient Chinese thought to better understand different ways of thinking. I want to create something universal, applicable not only to China, but the world.

The second factor is that Chinese scholars were fond of constructivism, relying heavily on Alexander Wendt's (Theory Talk\#3) 'Social Theory of International Politics', and had no interests in developing new theories. It is an important book, but we cannot rely on it forever. By 2005 I was already tired of Wendt's ideas, so I decided to pursue new theoretical studies. 
I am, first of all, a realist, so I find many faults in Wendt's theory, including two major problems: first, his theory cannot explain clearly the mechanism of mutual interaction, a core concept for his theory. He argues that the change of international norms is based on mutual interaction between states, but he cannot explain what changes what. Is it the people's concepts that change behavior or people's behavior that changes their concepts? Readers cannot really understand what mutual interaction is in essence. According to scientific standards, each step of mutual interaction should be clear: what happens first and what result does it lead to. The second problem is that his concept of the evolution of international norms is unilinear. I believe that is historically inaccurate. He believes that international norms evolve from the Hobbesian culture to Lockean culture and then to Kantian culture. In fact, human history never developed in a unilinear fashion. It might rather resemble a tree, branching out in all directions. So I have a problem with his view of history, and that was really one important factor which motivated me to study ancient Chinese thought. I want to know what the ancient Chinese thinkers thought about history, and how did they view the future of human society in two thousand years ago.

I got interested in pre-Qin history for various reasons. Growing up in China, we learn from a very young age about the Spring and Autumn period and the Warring States period, and the very complicated relationships among the powers of those periods. I think there is a similarity to the situation today. Three thousand years ago, the Western Zhou dynasty was like the US hegemon after the Cold War, a unipolar system. The Chinese term we would use for that is 王权 [wangquan]. After the Western Zhou Dynasty was the Spring and Autumn period there were some thirty countries within the realm, which by the Warring States period was reduced to seven, before being united as one country in the Qin Dynasty [in the third century BC]. This history is known by every Chinese kid.

So drawing a parallel between Chinese history and contemporary world politics, after the Cold War we entered a unipolar world, resembling the Zhou Dynasty. Where is it moving? Many people are talking about multipolarization. Multipolarization means a transfer from a unipolar configuration to a multipolar one, similar to the transfer from the Western Zhou domination to the Spring and Autumn period. Thus, I turned to considering what happened in that period, and what we might learn from the thinkers of that time. I didn't do a historical study, I didn't study the facts, I only studied the thought: how did the people in that time think about the world?

The third reason for me to study the ancient writings is very personal. Because I'm Chinese, my Western cultural background is lacking. It is difficult for me to understand that culture, because I did not grow up with it. But I'm familiar with the Chinese culture: I know international politics today are very different than two thousand years ago, but I also find some similarities between now and then. Perhaps we can get some important resources from ancient Chinese thought, to help us to develop theory - to help us to surpass Alexander Wendt. And recently, our group is growing. We have more and more people working to create theories of international relations by studying ancient Chinese thought. You may have noticed that we are publishing more and more theoretical articles in the CJIP many of which have more powerful explanatory power than that of Alexander Wendt.

\section{What would a student need to become a specialist in IR or understand the world in a global way?}

I like this question. There are two points I'd like to make. Once I encouraged some Indian scholars to follow our suit, to study IR from the perspective of their ancient history and their 
archaeology. India actually has a strong tradition of political thought dating back to ancient times, but now you find that the dominating IR theories are all based on Western culture. I think if we want IR theories to become truly rich and develop more universal values, we should encourage these scholars and students to take a deeper look into their own culture, knowledge, philosophy, and political theory, to enrich this field, as Amitev Acharya (Theory Talk.\#42) and others have argued, because this kind of study is severely lacking. Theoretical studies of international relations tend to rest mainly on European philosophies. Too few IR scholars read Chinese philosophy. It is much the same situation in India. The Indians have a very long history. So the Indian students, and also Latin American students, can bring their traditional thought into IR theory. I believe that this can deeply enrich and develop modern IR theory.

Second, and this is a more methodological point, I personally adhere to the scientific methodology, so I encourage my students to do positivist studies following the scientific method, but I do not oppose other methodologies. If they can develop a solid theory in another way I will support them in their endeavor. Personally, I believe at this moment that the scientific method is more efficient than any other, because it helps make theory clearer. Especially nowadays, the social sciences cannot just study the nature of relationships between humans, societies or nations, and conduct qualitative studies, but must implement quantitative methodologies. That means we need to study differences in degrees, not only differences in nature.

\section{In your recent book Ancient Chinese Thought, Modern Chinese Power (Princeton University Press, 2011), you differentiate between hegemonic power and what has been translated as 'humane authority'. What is the difference?}

The United States is a typical hegemon. Its conduct of foreign affairs is characterized by a double standard: a hegemon presents norms as the principle for dealing with its friends, but power politics as a principle for dealing with its enemies. A humane authority, by contrast, should have a coherent principle underpinning its behavior. That means it will make a judgment on whether a state is at fault or not, according to international norms rather than their personal relationship. 'Because you're a friend, you can do wrong. Because you are my enemy, no matter what you do, I am opposed to you.' That is the essence of a hegemon, but not a humane authority. Humane authority works differently by making judgments according to principles, unanimous criteria, and not using a double standard. Currently we cannot identify any major powers as a humane authority, but I do believe China ought to be this kind of state.

So what is important in becoming a humane authority? Of course, transparency is a very important issue here. If a government heavily relies on secret diplomacy, you can hardly expect it to play the role of a humane authority. Moreover, transparency is important not only internationally, but also at a domestic level. However, I think that it is important to note transparency is important, but not crucial. The core of a humane authority lies in credibility. Credibility means that you keep your promises and that your actions are consistent with your words.

Let me give an example. At this point in time they are debating in China whether we should abandon the non-alliance principle, which stipulates we do not make promises to anyone. Without offering any promises, there is no way to test your credibility. You promise nothing, so you do not need to meet any specific expectations. You can never know whether such a country has credibility or not, whether that country is reliable or not. If China wants to be a world power and play the role of the leading power then China has to make alliances. Without alliances you can never have close relations with other countries, and certainly can never have more good friends than the US. The US makes alliances, China doesn't. You can't find any country in the 
world that says, 'we have more close friends than the United States,' because there is no country that makes more alliances. Secondly, because the US makes alliances and makes promises to its allies, we can know how reliable or unreliable they are. When they don't keep their promises their allies aren't happy.

That's why I argue that at this moment for China to become a humane authority, it needs to consider giving up its non-alliance principle. China started its non-alliance principle in 1982 contrasting greatly from the ideas put forth in the Five Principles of Peaceful Coexistence. Previously, China had made alliances with many countries all over the world.

You strongly align yourself with the Realist school of IR, which underscores national selfinterest and prioritizes national interest and security over ideology and moral concerns, and indeed you accept that a 'true kingship' state must be strongly militarily. And yet a core theme of your book is 'moral authority' without military force. How do you reconcile these principles?

I should explain first of all that when I speak of the three different types of international leadership - tyranny, hegemony, and humane authority — all three types of leadership are based on military power. The main difference is in terms of their morality and the principles that govern their behavior. Even a humane authority leadership needs the support of military power.

If people have argued that I make a contradictory argument in my book, it is because people misunderstand realism. In realism, we consider morality to be an important part of power; it is an essential element of capabilities. When realists talk about capabilities, strength and power, they consider morality very important. Morgenthau is very typical in this regard: of his sixprinciples of political realism two are about morality!

I build my argument based on Morgenthau's writing on morality. First of all, morality can provide legitimacy for you to use force. Without morality, you use force illegally and undermine the strength of your military force, and you also make it very difficult to achieve political goals. Secondly_ and realists realize this very well-morality should be both constant and specific. An unspecific moral code provides an excuse for using violence and going to war, making such morality meaningless. Within realism, morality should be concrete, not simply an abstract concept.

Finally, it is important to consider the two most important variables in realism: power (or capabilities), and interest. People often misinterpret realism as being concerned only with economic interest. In fact, we define interests in a comprehensive way, and not as narrowly as only applied to the economic field! Political interests are more important for us than economic interests.

\section{And that is the point of your criticism of the Chinese government, whose current focus is} economic development.

Yes. And which school of IR theory gave the first priority to economic interests? Liberalism. Liberalism believes that economic interests should enjoy the first priority of the country's macropolicy, but in realism, economic interests are a secondary concern. National security interests should take precedence over economic concerns. Because we as realist view national security as paramount, we must be concerned with the moral character of our actions. If security interests are the most important concern then there should not be a contradiction of our policy with 
morality. Morality helps guide a nation's principles and even how and what national security policy it implements.

You speak of conflict repeatedly, and you started our conversation saying that there was competition and potential conflict between China and the United States. To what extent do you see the rise of China necessarily replacing the US as the predominant global power?

First of all, we realists don't believe the world can be harmonious. Even at the domestic level it is difficult to achieve complete harmony. Look at China as an example: the conflict between different social groups is serious; it is clear China has not achieved a harmonious society. Yet again, you can hardly say the US is a harmonious society! If you cannot even make a country internally harmonious, how can you make the international system harmonious? The Chinese government uses the term 'harmonious' a lot—we could say it's a concept like the Kantian idea of 'perpetual peace': it's desirable, but that doesn't mean you can achieve it. So instead of deploying such terms, it makes sense to speak of a less violent, less conflictive environment. So we realist commonly refer to less violence and less war as a desirable outcome, but we never talk about harmony.

The second thing is that in realism even if we do accept that term, we question the process: how might the world move closer towards a harmonious society? You need to develop new international norms. Before we argue what norms are more helpful, at minimum we have to admit that the norms of today cannot achieve harmony on a global scale. Reality tells us that the current norms are not good enough. We need to reform and create new international norms to govern the behavior of all nation states in order to make a relatively harmonious, or less conflictive international society.

Related to the topic of international norms, I as a realist believe is that no country is able to create a world government. On the one hand you cannot have a world government, on the other hand every power is greedy for leadership, which inevitably leads to a fight for power. How can this be addressed? You need norms. So you are looking at the gap between the desirable world government and the reality of the war among major powers, where norms are needed-not to govern, but to constrain behavior, to make states relatively peaceful. Today's international norms cannot meet the goal of relative peace and stability; they may fulfill some other functions, but are insufficient. So when I talk about humane authority, I mean that such authority should develop or create those much-needed new norms. To create new international norms there are three approaches: 'Make yourself an example', that means, make yourself a model for the world. Second: 'punish those who violate the norms'; and thirdly: 'protect and encourage those who abide by the norms'. If you cannot achieve your goal just by setting an example, then the second approach is acceptable.

In addition to the line of thought you are developing at Tsinghua University, there are a small handful of prominent Chinese scholars in the field. Are there any unifying ideas in the IR debates in China?

I think there are two major thinkers that matter here: Qin Yaqing and Zhao Tingyang. Actually I think there is some similarity between Qin Yaqing (Theory Talk \#45) and myself, and what Qin and me share is that we do not have a connection with Zhao Tingyang, because Zhao is a philosopher and his books are about philosophy, rather than about the real world. So although 
Western scholars take his work very seriously, as a part of China's IR thinking, in China we don't agree. We don't think his writing is in any way related to IR, it's a kind of philosophical exercise. In fact I find it quite strange that Western scholars consider his work as part of the China IR schools.

As for Qin, we are very close, but we have different approaches. The common thing we share is that we feel the need to borrow ancient Chinese thought as a resource to develop our theory. But Qin believes that we should develop a kind of theory that is typically Chinese, and that is not my view. We don't need something very Chinese; we just need to build something that is popular throughout the world. Secondly, Qin has tried to study the question of a specifically Chinese IR theory from within: he takes relationships between states as an independent variable, which is very different from me. I take international relations as a dependent variable: I think relationships are a result. It's not because of a relationship that a situation garners certain characteristics, rather it is the inverse: because of a situation we have a relationship. I work out how to deal with power, how to deal with norms, how to deal with interests, and this is how to make the relationship harmonious. Qin develops 'relationship theory'. If you look at the details, you will also find much we have in common. For instance, his method of study is also very scientific; both of us use the scientific method. On that basis, it is easy for us to communicate with each other.

How much does IR theory influence policy? Or, to make that more concrete, to what extent do you believe your thinking has an influence on government policy? You have noted that there are no independent policy think tanks in China, and yet Tsinghua University and other institutions do have some considerable influence.

I think there are three ways in which scholars' opinions may influence China's foreign policy making. First of all, there are academic publications like Wang Jisi's recent report 'China's Search for a Grand Strategy', and my own articles. This stimulates debate as policy makers read our articles and gain insight into our ideas. The second factor consists of internal meetings: policy bureaus always call on scholars to join meetings and there are discussions. Through these discussions they will be influenced by the universities. A third important factor is the individual contact some of us have with policy makers.

Earlier this year we held a forum to discuss why the term 'reform' can never be applied to China's foreign policy. The term reform has been very popular in China, having been applied to the economy, to medicine, to education - to pretty much everything. However, 'reform' has not been applied to foreign policy. However, my personal take on this is that whatever the differences may be among scholars in our field, they all agree that we need reform of the current Chinese foreign policy. The current foreign policy has a problem, and needs reform to become more efficient. People may have different views, but the need for reform is unanimously accepted within the scholarly community. This is my hope for the new government. I don't know what kind of policy they are going to adopt, but one thing is clear, they cannot continue the current policy. In the early 1990s, the late paramount leader Deng Xiaoping gave guidance to China's foreign and security policy apparatus that, collectively, has come to be known as the ' 24 character strategy': 'observe calmly; secure our position; cope with affairs calmly; hide our capacities and bide our time; be good at maintaining a low profile; and never claim leadership'. Yet in my view, 'Keeping a low profile', a key element of Deng Xiaoping's 24-character strategy from the 1990's, is out of date.

\section{To what extent can China take a leading position globally?}


I know what you want to address, but I think most foreigners ignore and misunderstand what the Chinese policy makers really are concerned with. Western countries wonder what kind of leadership China is going to provide. Actually, this is very strange for a Chinese policy maker: 'wait a minute, our policy is that we won't provide any leadership. We don't want to take on the leadership!' For China it is not a question of what type of leadership we might want to provide. What I discuss in my book is far from what the Chinese government is actually thinking about. What they discuss is whether we should take on a leadership role in the first place. So from my understanding, the debate for the next government is not what policy we should adopt or what kind of international norms we should offer. The question is: should China offer international norms? Should China take on international responsibility? Should China become the leader? Should China become a superpower? Before we discuss how we might go about leading we must answer these questions.

Yan Xuetong is Dean of the Institute of Modern International Relations at Tsinghua University in Beijing and the Chief Editor of The Chinese Journal of International Politics (Oxford University Press). Professor Yan received his PhD in political science from the University of California, Berkeley in 1992. In 2008, Yan was named as one of the world's Top 100 public intellectuals by the American journal Foreign Policy. Yan has published extensively, most recently Ancient Chinese Thought, Modern Chinese Power, Princeton University Press 2011.

- Yan Xuetong's Faculty Profile at Tsinghua University

- Read the Introduction to Xuetong's Ancient Chinese Thought, Modern Chinese Power here(pdf)

- Read Xuetong's How China Can Defeat America (New York Times, 2011) here (html)

- Read Xuetong's The Rise of China in China's Eyes (Journal of Contemporary China, 2001), here (pdf)

- Read Xuetong's Analysis of China's National Interest (full book, 1999) here (pdf) 